\title{
Vitamin D and Number of Falls in a Long-Term Care Facility
}

\author{
Robert B. Raffa ${ }^{1 *}$, Frank Breve ${ }^{2}$, Robert Taylor Jr. ${ }^{3}$, Joseph V. Pergolizzi Jr., ${ }^{4,5,6}$ \\ ${ }^{1}$ Temple University School of Pharmacy, Philadelphia, USA; ${ }^{2}$ Mid Atlantic Pharma Tech Consultants, LLC, Ventnor City, USA; \\ ${ }^{3}$ NEMA Research Inc., Naples, USA; ${ }^{4}$ Temple University School of Medicine, Temple University, Philadelphia, USA; ${ }^{5}$ School of \\ Medicine, The Johns Hopkins University, Baltimore, USA; ${ }^{6}$ School of Medicine, Georgetown University, Washington USA. \\ Email: *robert.raffa@temple.edu
}

Received June $27^{\text {th }}, 2012$; revised July $28^{\text {th }}, 2012$; accepted August $10^{\text {th }}, 2012$

\begin{abstract}
Falls represent a significant contribution to the morbidity and mortality of the elderly population. Because vitamin D is important in bone physiology, the use of vitamin $\mathrm{D}$ to restore deficient bone and ameliorate the effects of bone fractures due to falls has become a common practice in recent years. Following introduction of widespread use, reports began to emerge that vitamin D not only aided in repair of fall-induced bone fractures, but that it also reduced the occurrence of falls. Vitamin D now has become a routine intervention as a fall-prevention measure. Early analyses found evidence of prevention efficacy (reduced falls), but recent analyses are more equivocal. We retrospectively examined the records of 350 patients in a long-term care facility in which vitamin $\mathrm{D}$ administration and the number of falls were recorded as part of a comprehensive database of care. We found a dramatic rise in vitamin D use over the period covered (2006-2011) and a corresponding dramatic decrease in the number of falls. However, the number of falls continued to decline after 2008 , despite a plateau in number of patients on vitamin D, particularly females. It appears that other factors contribute to the overall decline.
\end{abstract}

Keywords: Falls; Bone Fracture; Vitamin D; Long-Term Care Facility

\section{Introduction}

Already by 1987 strategies to address the morbidity and mortality associated with falls in the elderly and others in which osteoporosis is common (such as postmenopausal women) advocated optimization of calcium absorption, a process in which vitamin D plays an important role [1]. Vitamin D also aids in bone growth and bone remodeling by osteoblasts and osteoclasts (for review, see [2]). The two major forms of the several forms of vitamin D are the secosteroids vitamin $\mathrm{D}_{2}$ (ergocalciferol, a derivative of ergosterol) and vitamin $\mathrm{D}_{3}$ (cholecalciferol, produced by UV irradiation of its precursor 7-dehydrocholesterol). As used here, vitamin D (without a subscript) refers to $D_{2}$, $\mathrm{D}_{3}$, or both. The active form of vitamin $\mathrm{D}$, calcitriol, binds to the VDR (vitamin D receptor), which acts as a transcription factor that modulates the gene expression of transport factors including TRPV6 (a transient receptor potential cation channel) and calbindin (calcium-binding protein), which are involved in the absorption of calcium from the intestine [3]. An insufficient amount of vitamin D (calcium) leads to osteoporosis and bone brittleness that predisposes the individual to bone fractures during

${ }^{*}$ Corresponding author. falls [4]. Since few foods contain significant amounts of vitamin $\mathrm{D}$, the diet is not usually a major source (unless fortified with the vitamin). Thus an exposure to sunshine, which promotes endogenous synthesis of vitamin D from cholesterol [5], is important. Situations that tend to limit exposure to the sun, increase the likelihood that vitamin D levels can drop below optimal levels [6].

An increasing incidence of fall-related bone fractures, in particular of the hip, has been associated with the ageing population [7]. Since vitamin D is believed to have only minimal toxicity, even at very large doses [8], vitamin D supplementation - usually with concomitant calcium - has become a common guideline recommendation and practice (e.g., [9-18]). Reports support beneficial effects of vitamin D supplementation. As an example, a meta-analysis of double-blinded randomized controlled trials examined the efficacy of supplemental vitamin D alone or with calcium in preventing falls in older populations [19]. Based on the trials that met the inclusion criteria, falls were not significantly reduced $(p>0.05)$ in those who received a low dose of supplemental vitamin $\mathrm{D}$ (200 - $600 \mathrm{IU} /$ day), but those who received a high dose (700 - $1000 \mathrm{IU} /$ day) had significantly reduced risk of fall 
$(p<0.05)$ of $19 \%$. In a retrospective review of nine studies that included vitamin D (800 IU) and calcium (1200 IU) supplementation in nursing home residents, a population that falls more than 10-times more frequently than their age-matched community-dwelling counterparts, supplementation improved bone mineral density and reduced fracture risk [20] (the topic is reviewed in [21]). Similar positive findings were reported by others for older adults [22] and female stroke survivors in institutional settings [23]. Doses even greater than $700-1000$ IU have been suggested for individuals with more severe vitamin D deficiency and those who are overweight [24].

However, a 15-year literature overview [25] points out that the literature is not universal in showing a beneficial effect. Some studies have failed to show any significant effect and alternative explanations have been offered. In light of this, we examined the records of a long-term care facility that had detailed records of falls and vitamin D supplementation over the period 2006-2011.

\section{Materials and Methods}

\subsection{Description of Facility}

The facility selected for data source is a county-owned, not-for-profit, 300-bed long-term care facility located in southern $\mathrm{NJ}$ with a $99 \%$ average census rate comprised of six nursing units, including a rehabilitation unit. The rehabilitation unit has a high admission turnover rate, which effectively brings the average monthly facility census rate to 350 residents.

\subsection{Data Sources}

All data were collected from the facility's fully integrated EMR (electronic medical records) computerized system, MEDITECH ${ }^{\mathrm{TM}}$ (Westwood, MA) and compiled from the computer-generated reports of residents who received vitamin $\mathrm{D}$ and documented fall incident during the six- year period starting January 1, 2006 and ending December 31, 2011.

\subsection{Data Extraction}

The relevant computer records were examined and each resident's age, sex, and vitamin D usage was recorded. The number of documented falls during each of the same years was obtained. All data were de-identified and are in compliance with the Health Insurance Portability and Accountability Act (HIPAA) requirements. The protocol was submitted to the Institutional Review Board (IRB) (granted waiver).

\section{Results}

In the first year for which there were complete records of both vitamin D supplementation and falls, 2006, the total number of residents receiving some form of a vitamin D supplement was 35 , of which 33, were female (35- 101 y.o.) and only 2 were males (58 - 79 y.o.). This number represents $10 \%$ of the total population and corresponds to a year in which a number of reviews were published on the use of vitamin D supplements for prevention of falls (e.g., [17,26-30]). The most common supplement regimen consisted of a $500 \mathrm{mg}$ tablet of vitamin $\mathrm{D}$ given b.i.d. with calcium. Other regimens involved vitamin D 1000 or $2000 \mathrm{IU}$ or calcitriol $0.25,0.5,1.0$ or $2.0 \mu \mathrm{g}$ daily, t.i.d., q.d., or on alternate days. The total number of falls during 2006 was 681 , that is, almost 2 falls per resident.

The number of residents on vitamin D supplements grew significantly in 2007 to 66 (52 females, 40 - 97 y.o.; 14 males, 73 - 92 y.o.) and 2008 to 92 (75 females). During this time the total number of falls fell to 641 (about 6\%) and 628 (about 8\%), respectively.

The number of females receiving a calcium + vitamin D supplementation regimen essentially plateaued in 2008 (75; 38 - 103 y.o.), 2009 (77; 38 - 96 у.o.), 2010 (75; 23 101 y.o.), and 2011 (77; 24 - 97 y.o.). The number of males on supplementation grew modestly up till 2010 : 2008 (17; 48 - 91 y.o.), 2009 (20; 56 - 93 у.о.), 2010 (26; 49 - 92 y.o.), 2011 (24; 39 - 92 y.o.).

Despite the plateau in total number of residents on vitamin D supplementation (reaching about 30\% in 2011), the number of falls continued to decline to 484 (less than 1.5 per resident) in 2011 (Figure 1).

\section{Discussion}

Each year, about a third of adults in the US who are over 65 y.o. will experience a fall [31-33]. Those over 80 y.o.

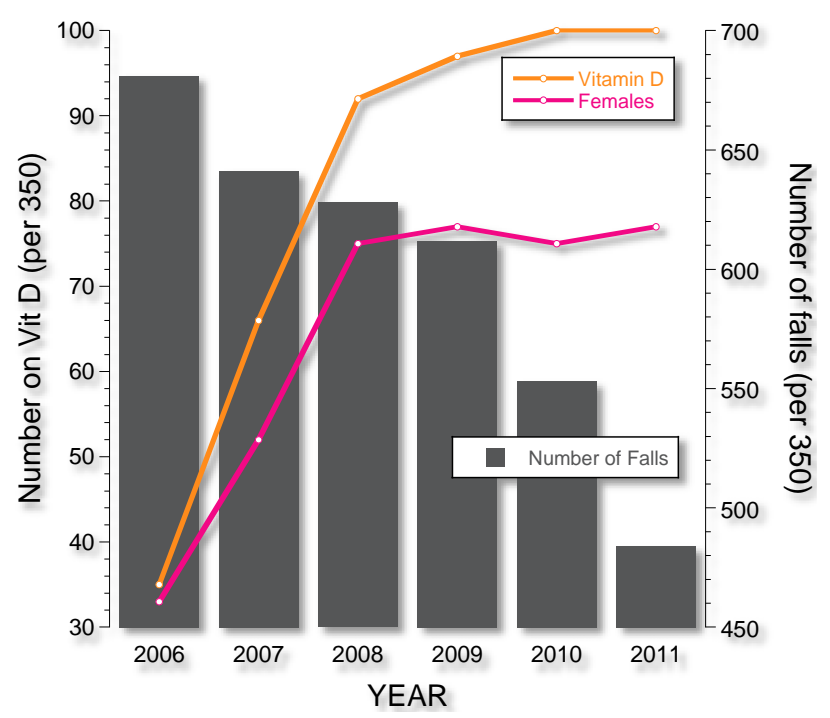

Figure 1. Relationship between number residents in a longterm care facility and number of falls during the years 2006-2011. 
have a risk almost $50 \%$ [34]. Some common risk factors include osteoporosis, lack of physical activity, impaired vision, sedative-producing medications, and fall-related hazards; thus females are at greater risk than males and those in long-term care facilities are at greater risk than those in community settings [35]. The consequences are both medical (injury) and psychological (distress). Bone fractures (mainly of hip or head) are the most common injuries, leading to hospitalization, disability, admission to nursing homes or long-term care facilities, increase in healthcare costs [36], and even early death [37]. About $25 \%$ of those who experience a hip fracture need some extended nursing care; about half of those hospitalized are discharged to nursing homes rather than to their own home [38]. Approximately 95,000 deaths of older adults each year in the US are attributed to falls and about one fourth of those who experience a hip fracture die within six months [38]. Thus, any intervention that strengthens bone, enhances recovery, or better still, prevents falls, is highly desirable and needed.

Several systematic reviews and meta-analyses have reported that supplementation with vitamin $\mathrm{D}$, and usually also calcium, decreases the number of falls in susceptible populations. The potential beneficial effects of such supplementation on the healing of bone fractures that result from falls seem straight- forward because of the important roles that calcium plays in bone health and healing and that vitamin D plays in calcium absorption. Several studies have reported positive results (reviewed in [39]). In one large study [40], in which over 3000 women (mean age 84 y.o.) living in facilities for the elderly were randomized to receive either daily vitamin $\mathrm{D}$ (800 IU + calcium (1.2 g) or placebo, decreased risk of hip fracture was found, which was sustained at a 3-year follow-up [41]. In another large randomized study [42] of more than 9000 community-dwelling elderly, vitamin D $(800 \mathrm{IU})+$ calcium $(1000 \mathrm{mg})$ reduced fracture risk in women, but there was no benefit in men (an observation noted in more than one such study). There is less evidence for efficacy of vitamin D alone (without calcium). A low dose of vitamin D (400 IU) daily increased bone density, but there was no reduction in fractures [43]. Higher doses, such as oral 100,000 IU every four months [44] or annual intramuscular injection of 150,000 300,000 [45] resulted in reductions in fracture risk.

The perception of lack of serious toxic consequence of vitamin D supplementation fosters its use even in absence of definitive proof of therapeutic efficacy in a particular application. The estimated tolerable daily intake of vitamin D is 4000 IU for those more than 9 y.o. (including pregnant or lactating women) [46]. The intake of more than 50,000 IU $(1250 \mu \mathrm{g})$ over several months can produce overt toxicity. The main symptoms of vitamin D overdose are those of hypercalcemia $(\geq 40,000$
IU daily) [47].

An ability of vitamin D with or without calcium to prevent falls, not just to prevent or heal fractures, is seemingly less obvious. One putative mechanism is that fractures lead to, rather than result from, falls. The present study examined the existing records of a longterm care facility for a correlation between vitamin D supplementation and the number of falls. The data were blinded in the sense that all of the recording of the information was not intended for research purposes and was collected by a number of different individuals, each unaware of the eventual use. The data reveal a very large increase in the use of vitamin D supplementation, always with calcium, starting in 2006 (about $10 \%$ of the residents) and continuing in 2007, and 2008 (more than $25 \%$ of residents). During these same years the number of falls progressively declined, seemingly providing strong support of a beneficial effect of vitamin $\mathrm{D}$ (or at least of a combination of vitamin $\mathrm{D}+$ calcium) in preventing falls. However, the number of falls continued to decline during 2009, 2010, and 2011 despite the fact that the number (percentage) of the female residents given vitamin D supplementation plateaued in the period 2008-2011 and there was only a small increase in the total number (females + males). This suggests that the vitamin D (+calcium) supplementation might not have been causative, but only incidental, to decline in number of falls. Data regarding the occurrence or the consequence of any fractures that resulted from these falls, which is the most likely beneficial effect of vitamin $\mathrm{D}+$ calcium supplementation, is not available. Another possible explanation for continued decline in number of falls is that the residents might have been transitioned to medications that had less propensity to cause falls.

\section{Conclusions}

In the present retrospective review of the computer records of a 350-residential (majority female) long-term care facility, vitamin D (most commonly $500 \mathrm{mg}$ b.i.d.) + calcium supplementation was closely correlated with a decreased number of falls during the period 2006-2008, consistent with studies that report a beneficial effect of vitamin D on prevention of falls. However, the continued decline in number of falls during the period 2009-2011, despite lack of a significant increase in the number of residents receiving supplementation, raises doubts about the assignment of causation.

The most effective intervention to prevent falls is a multifactorial assessment and management program that includes a vitamin $\mathrm{D}$ supplementation regimen with or without calcium [44,48-50], particularly in institutionalized elderly women who are the most likely to have vitamin D deficiency and secondary hyperparathyroidism [39]. 


\section{REFERENCES}

[1] F. Heidrich and R. S. Thompson, "Osteoporosis Prevention: Strategies Applicable for General Population Groups," Journal of Family Practice, Vol. 25, No. 1, 1987, pp. 3339.

[2] E. Laird, M. Ward, E. McSorley, J. J. Strain and J. Wallace, "Vitamin D and Bone Health: Potential Mechanisms," Nutrients, Vol. 2, No. 7, 2010, pp. 693-724. doi:10.3390/nu2070693

[3] R. Bouillon, S. Van Cromphaut and G. Carmeliet, "Intestinal Calcium Absorption: Molecular Vitamin D Mediated Mechanisms," Journal of Cellular Biochemistry, Vol. 88, No. 2, 2003, pp. 332-339. doi:10.1002/jcb.10360

[4] P. Lips and N. M. van Schoor, "The Effect of Vitamin D on Bone and Osteoporosis," Best Practice and Research Clinical Endocrinology \& Metabolism, Vol. 25, No. 4, 2011, pp. 585-591. doi:10.1016/j.beem.2011.05.002

[5] O. Engelsen, "The Relationship between Ultraviolet Radiation Exposure and Vitamin D Status," Nutrients, Vol. 2, No. 5, 2010, pp. 482-495. doi:10.3390/nu2050482

[6] B. A. Gilchrest, "Sun Exposure and Vitamin D Sufficiency," American Journal of Clinical Nutrition, Vol. 88, No. 2, 2008, pp. 570S-577S.

[7] M. D'Imporzano, F. M. Liuni and U. Tarantino, "Acetabular Fragility Fractures in Elderly Patients," Aging Clinical and Experimental Research, Vol. 23, Suppl. 2, 2011, pp. 71-73.

[8] D. W. Stephenson and A. N. Peiris, "The Lack of Vitamin D Toxicity with Megadose of Daily Ergocalciferol (D2) Therapy: A Case Report and Literature Review," Southern Medical Journal, Vol. 102, No. 7, 2009, pp. 765-768. doi:10.1097/SMJ.0b013e3181a8d1e4

[9] J. J. Body, P. Bergmann, S. Boonen, Y. Boutsen, O. Bruyere, J. P. Devogelaer, S. Goemaere, N. Hollevoet, J. M. Kaufman, K. Milisen, S. Rozenberg and J. Y. Reginster, "Non-Pharmacological Management of Osteoporosis: A Consensus of the Belgian Bone Club," Osteoporos International, Vol. 22, No. 11, 2011, pp. 2769-2788.

[10] T. P. Ip, J. Leung and A. W. Kung, "Management of Osteoporosis in Patients Hospitalized for Hip Fractures," Osteoporosis International, Vol. 21, No. 4, 2010, pp. 605614. doi:10.1007/s00198-010-1398-8

[11] P. Geusens, "Strategies for Treatment to Prevent Fragility Fractures in Postmenopausal Women," Best Practice and Research in Clinical Rheumatology, Vol. 23, No. 6, 2009, pp. 727-740. doi:10.1016/j.berh.2009.09.001

[12] M. G. Sweet, J. M. Sweet, M. P. Jeremiah and S. S. Galazka, "Diagnosis and Treatment of Osteoporosis," American Family Physician, Vol. 79, No. 3, 2009, pp. 193-200.

[13] D. L. Schneider, "Management of Osteoporosis in Geriatric Populations," Current Osteoporosis Reports, Vol. 6, No. 3, 2008, pp. 100-107. doi:10.1007/s11914-008-0018-4

[14] C. Roux, H. A. Bischoff-Ferrari, S. E. Papapoulos, A. E. de Papp, J. A. West and R. Bouillon, "New Insights into the Role of Vitamin D and Calcium in Osteoporosis Management: An Expert Roundtable Discussion," Current Medical Research and Opinion, Vol. 24, No. 5, 2008, pp. 1363-1370. doi:10.1185/030079908X301857
[15] J. T. Lin and J. M. Lane, "Nonpharmacologic Management of Osteoporosis to Minimize Fracture Risk," Nature Clinical Practice Rheumatology, Vol. 4, No. 1, 2008, pp. 20-25. doi:10.1038/ncprheum0702

[16] S. L. Kates, O. S. Kates and D. A. Mendelson, "Advances in the Medical Management of Osteoporosis," Injury, Vol. 38, Suppl. 3, 2007, pp. S17-S23. doi:10.1016/j.injury.2007.08.007

[17] J. P. Levine, "Pharmacologic and Nonpharmacologic Management of Osteoporosis," Clinical Cornerstone, Vol. 8, No. 1, 2006, pp. 40-53. doi:10.1016/S1098-3597(06)80064-5

[18] S. L. Follin and L. B. Hansen, "Current Approaches to the Prevention and Treatment of Postmenopausal Osteoporosis," American Journal of Health System Pharmacists, Vol. 60, No. 9, 2003, pp. 883-901.

[19] H. A. Bischoff-Ferrari, B. Dawson-Hughes, H. B. Staehelin, J. E. Orav, A. E. Stuck, R. Theiler, J. B. Wong, A. Egli, D. P. Kiel and J. Henschkowski, "Fall Prevention with Supplemental and Active Forms of Vitamin D: A Meta-Analysis of Randomised Controlled Trials," British Medical Journal, Vol. 339, 2009, p. b3692. doi:10.1136/bmj.b3692

[20] S. Parikh, J. Avorn and D. H. Solomon, "Pharmacological Management of Osteoporosis in Nursing Home Populations: A Systematic Review," Journal of the American Geriatrics Society, Vol. 57, No. 2, 2009, pp. 327-334. doi:10.1111/j.1532-5415.2008.02119.x

[21] C. Becker and K. Rapp, "Fall Prevention in Nursing Homes," Clinical in Geriatric Medicine, Vol. 26, No. 4, 2010, pp. 693-704. doi:10.1016/j.cger.2010.07.004

[22] R. R. Kalyani, B. Stein, R. Valiyil, R. Manno, J. W. Maynard and D. C. Crews, "Vitamin D Treatment for the Prevention of Falls in Older Adults: Systematic Review and Meta-Analysis," Journal of the American Geriatrics Society, Vol. 58, No. 7, 2010, pp. 1299-1310. doi:10.1111/j.1532-5415.2010.02949.x

[23] F. Batchelor, K. Hill, S. Mackintosh and C. Said, "What Works in Falls Prevention after Stroke? A Systematic Review and Meta-Analysis," Stroke, Vol. 41, No. 8, 2010, pp. 1715-1722. doi:10.1161/STROKEAHA.109.570390

[24] H. Bischoff-Ferrari, "Vitamin D: What Is an Adequate Vitamin D Level and How Much Supplementation Is Necessary?" Best Practice and Research Clinical Rheumatology, Vol. 23, No. 6, 2009, pp. 789-795. doi:10.1016/j.berh.2009.09.005

[25] C. Annweiler, M. Montero-Odasso, A. M. Schott, G. Berrut, B. Fantino and O. Beauchet, "Fall Prevention and Vitamin D in the Elderly: An Overview of the Key Role of the Non-Bone Effects," Journal of Neuroengineering and Rehabilitation, Vol. 7, No. 1, 2010, p. 50. doi:10.1186/1743-0003-7-50

[26] E. M. Lewiecki and S. L. Silverman, "Redefining Osteoporosis Treatment: Who to Treat and How Long to Treat," Arquivos Brasileiros de Endocrinologia \& Metabologia, Vol. 50, No. 4, 2006, pp. 694-704. doi:10.1590/S0004-27302006000400015

[27] C. G. Swift, "The Role of Medical Assessment and Intervention in the Prevention of Falls," Age and Ageing, Vol. 
35, Suppl. 2, 2006, pp. ii65-ii68. doi:10.1093/ageing/af1083

[28] K. F. Mauck and B. L. Clarke, "Diagnosis, Screening, Prevention, and Treatment of Osteoporosis," Mayo Clinic Proceedings, Vol. 81, No. 5, 2006, pp. 662-672.

[29] M. Gass and B. Dawson-Hughes, "Preventing Osteoporosis-Related Fractures: An Overview," American Journal of Medicine, Vol. 119, No. 4, 2006, pp. S3-S11. doi:10.1016/j.amjmed.2005.12.017

[30] E. S. Siris, "Patients with Hip Fracture: What Can Be Improved?" Bone, Vol. 38, No. 2, 2006, pp. 8-12. doi:10.1016/j.bone.2005.11.014

[31] J. M. Hausdorff, D. A. Rios and H. K. Edelberg, "Gait Variability and Fall Risk in Community-Living Older Adults a 1-Year Prospective Study," Archives of Physical Medicine and Rehabilitation, Vol. 82, No. 8, 2001, pp. 1050-1056. doi:10.1053/apmr.2001.24893

[32] M. E. Tinetti, M. Speechley and S. F. Ginter, "Risk Factors for Falls among Elderly Persons Living in the Community," New England Journal of Medicine, Vol. 319, No. 26, 1988, pp. 1701-1707. doi:10.1056/NEJM198812293192604

[33] J. T. Chang, S. C. Morton, L. Z. Rubenstein, W. A. Mojica, M. Maglione, M. J. Suttorp, E. A. Roth and P. G. Shekelle, "Interventions for the Prevention of Falls in Older Adults: Systematic Review and Meta-Analysis of Randomised Clinical Trials," British Medical Journal, Vol. 328, No. 7441, 2004, p. 680. doi:10.1136/bmj.328.7441.680

[34] A. J. Blake, K. Morgan, M. J. Bendall, H. Dallosso, S. B. Ebrahim, T. H. Arie, P. H. Fentem and E. J. Bassey, "Falls by Elderly People at Home: Prevalence and Associated Factors," Age and Ageing, Vol. 17, No. 6, 1988, pp. 365-372. doi:10.1093/ageing/17.6.365

[35] P. C. Walker, A. Alrawi, J. F. Mitchell, R. E. Regal and U. Khanderia, "Medication Use as a Risk Factor for Falls among Hospitalized Elderly Patients," American Journal of Health System Pharmacists, Vol. 62, No. 23, 2005, pp. 2495-2499. doi:10.2146/ajhp050116

[36] B. H. Alexander, F. P. Rivara and M. E. Wolf, "The Cost and Frequency of Hospitalization for Fall-Related Injuries in Older Adults," American Journal of Public Health, Vol. 82, No. 7, 1992, pp. 1020-1023. doi:10.2105/AJPH.82.7.1020

[37] J. E. Dunn, S. E. Furner and T. P. Miles, "Do Falls Predict Institutionalization in Older Persons? An analysis of Data from the Longitudinal Study of Aging," Journal of Aging Health, Vol. 5, No. 2, 1993, pp. 194-207. doi:10.1177/089826439300500203

[38] C. Casteel, C. Peek-Asa, C. Lacsamana, L. Vazquez and J. F. Kraus, "Evaluation of a Falls Prevention Program for Independent Elderly," American Journal of Health Behavior, Vol. 28, Suppl. 1, 2004, pp. S51-S60. doi:10.5993/AJHB.28.s1.6

[39] R. M. Francis, "Calcium, Vitamin D and Involutional Osteoporosis," Current Opinion in Clinical Nutrition and Metabolic Care, Vol. 9, No. 1, 2006, pp. 13-17.
[40] M. C. Chapuy, M. E. Arlot, F. Duboeuf, J. Brun, B. Crouzet, S. Arnaud, P. D. Delmas and P. J. Meunier, "Vitamin D3 and Calcium to Prevent Hip Fractures in the Elderly Women," New England Journal of Medicine, Vol. 327, No. 23, 1992, pp. 1637-1642. doi:10.1056/NEJM199212033272305

[41] M. C. Chapuy, M. E. Arlot, P. D. Delmas and P. J. Meunier, "Effect of Calcium and Cholecalciferol Treatment for Three Years on Hip Fractures in Elderly Women," British Medical Journal, Vol. 308, No. 6936, 1994, pp. 1081-1082. doi:10.1136/bmj.308.6936.1081

[42] B. Dawson-Hughes, S. S. Harris, E. A. Krall and G. E. Dallal, "Effect of Calcium and Vitamin D Supplementation on Bone Density in Men and Women 65 Years of Age or Older," New England Journal of Medicine, Vol. 337, No. 10, 1997, pp. 670-676. doi:10.1056/NEJM199709043371003

[43] P. Lips, W. C. Graafmans, M. E. Ooms, P. D. Bezemer and L. M. Bouter, "Vitamin D Supplementation and Fracture Incidence in Elderly Persons: A Randomized, Placebo-Controlled Clinical Trial," Annals of Internal Medicine, Vol. 124, No. 4, 1996, pp. 400-406.

[44] A. Avenell, W. J. Gillespie, L. D. Gillespie and D. O'Connell, "Vitamin D and Vitamin D Analogues for Preventing Fractures Associated with Involutional and Post-Menopausal Osteoporosis," Cochrane Database of Systematic Reviews, No. 2, 2009, Article No. CD000227.

[45] R. J. Heikinheimo, J. A. Inkovaara, E. J. Harju, M. V. Haavisto, R. H. Kaarela, J. M. Kataja, A. M. Kokko, L. A. Kolho and S. A. Rajala, "Annual Injection of Vitamin D and Fractures of Aged Bones," Calcified Tissue International, Vol. 51, No. 2, 1992, pp. 105-110. doi:10.1007/BF00298497

[46] A. C. Ross, J. E. Manson, S. A. Abrams, J. F. Aloia, P. M. Brannon, S. K. Clinton, R. A. Durazo-Arvizu, J. C. Gallagher, R. L. Gallo, G. Jones, C. S. Kovacs, S. T. Mayne, C. J. Rosen and S. A. Shapses, "The 2011 Report on Dietary Reference Intakes for Calcium and Vitamin D from the Institute of Medicine: What Clinicians Need to Know," Journal of Clinical Endocrinology and Metabolism, Vol. 96, No. 1, 2011, pp. 53-58. doi:10.1210/jc.2010-2704

[47] R. Vieth, "Vitamin D Supplementation, 25-Hydroxyvitamin D Concentrations, and Safety," American Journal of Clinical Nutrition, Vol. 69, No. 5, 1999, pp. 842-856.

[48] L. D. Gillespie, M. C. Robertson, W. J. Gillespie, S. E. Lamb, S. Gates, R. G. Cumming and B. H. Rowe, "Interventions for Preventing Falls in Older People Living in the Community," Cochrane Database of Systematic Reviews, 2009, Article No. CD007146.

[49] I. D. Cameron, G. R. Murray, L. D. Gillespie, M. C. Robertson, K. D. Hill, R. G. Cumming and N. Kerse, "Interventions for Preventing Falls in Older People in Nursing Care Facilities and Hospitals," Cochrane Database of Systematic Reviews, No. 1, 2010, Article No. CD005465.

[50] C. A. Nowson, "Prevention of Fractures in Older People with Calcium and Vitamin D," Nutrients, Vol. 2, No. 9, 2010, pp. 975-984. doi:10.3390/nu2090975 